\title{
OS CONTOS DE FADAS E A PRÁTICA PSICOPEDAGÓGICA: PERSPECTIVAS DE ANÁLISE EM DEBATE
}

\author{
FAIRY TALES AND PSYCHOPEDAGOGICAL PRACTICE: PERSPECTIVES OF \\ ANALYSIS UNDER DISCUSSION
}

\author{
Silvia Aparecida Santos de Carvalho ${ }^{1}$ \\ Instituto Sedes Sapientiae
}

\section{Introdução}

Considerando a pertinência dos contos de fadas para o processo de intervenção psicopedagógica, o presente exercício de elaboração se propõe a apresentar possíveis relações entre estudos que se ocuparam com a fecundidade desses contos e que foram produzidos no terreno investigatório da história cultural, na área da Psicologia Analítica e na área da Psicanálise.

Mesmo compreendendo que as perspectivas de análise, colocadas em diálogo, pertençam a matrizes teóricas diferentes, esse exercício de elaboração ocupou-se em encontrar aproximações e afastamentos observáveis nessa relação. A intenção é, com esse movimento de análise, contribuir com a formação dos profissionais da psicopedagogia que consideram os contos de fadas um instrumento significativo para o processo de intervenção psicopedagógica.

A partir, então, dessas considerações, a perspectiva de análise aqui adotada se desenvolve nos limites de um texto inicial, um ensaio, que indica um ponto de vista. Passível de questionamento se configura como um texto que se propõe a suscitar o debate e se, assim, motivar outras elaborações terá ido além da sua proposição primeira.

As contribuições que iniciam esse processo de elaboração são as apresentadas nos estudos empreendidos por Robert Darton. Professor na Universidade de Princeton e sob a influência de estudos ligados a antropologia, publicou em 1986, "O grande massacre de gatos e outros episódios da história cultural francesa" no qual se dedica a analisar as maneiras de pensar na França do século XVIII. Rompendo com a tradição da história intelectual, Darton opta por encaminhar sua análise pelo território ainda muito pouco explorado, conhecido na França como história das mentalidades, que ao gosto inglês, denominou-se de história cultural. E para buscar não apenas o que as pessoas pensavam naquela época, mas como elas pensavam, utilizou-se dos contos narrados nas rodas camponesas no século XVII e XVIII por entender que essas narrativas poderiam revelar muito do universo mental daqueles grupos sociais.

\footnotetext{
${ }^{1}$ Doutora em Educação. Psicopedagoga. Professora do Curso de Especialização em Psicopedagogia Clínica e Institucional do Instituto Sedes Sapientiae. Autora de livros e artigos em Educação.
} 
A análise empreendida por Darton (1986) motivou a busca de compreensões referenciadas em outras perspectivas de análise. Dois estudos referenciados teoricamente pela Psicologia Analítica, desenvolvidos por Marie Louise von Franz, em "A interpretação dos Contos de Fadas" (1981) e por Jette Bonaventure, em “O que conta o conto?" (1992), e estudos desenvolvidos por Diana Corso e Mário Corso (2006) no campo da Psicanálise são abordados aqui e, no cotejo das compreensões que apresentam, são identificadas possíveis aproximações e afastamentos que certamente qualificam e ampliam as compreensões sobre os usos possíveis desses contos no processo de intervenção psicopedagógica.

O leitor que, porventura, aceitar o convite à leitura, certamente não perderá por acompanhar o desenvolvimento da análise aqui empreendida. Ora, sabemos que a floresta oferece diversos caminhos e que se não nos aventurarmos a prosseguir não desfrutaremos da casa de doces e de todas as oportunidades de crescimento que ela pode nos oferecer!!

\section{Os Contos de Fadas por diferentes perspectivas de análise}

É recorrente entre os profissionais da psicopedagogia a ideia de que os contos de fadas podem trazer significativa contribuição para o desenvolvimento do trabalho psicopedagógico. Contudo, é de fundamental importância identificar que muitos dos contos que ainda são contados e lidos atualmente foram recolhidos da tradição oral camponesa europeia, num mundo muito diferente do nosso e que, por isso, uma análise sobre eles não pode dispensar sua dimensão histórica.

Alguns estudos históricos sobre contos, que remontam a longa duração, de tempos bastante distantes do nosso, em que eram narrados por camponeses ao redor da lareira, são muito significativos, especialmente os estudos produzidos na perspectiva da história cultural. Determinados em compreender o território pouco explorado da sociedade iluminista, dos séculos XVII e XVIII, se ocupando em identificar o que e como as pessoas pensavam, como interpretavam o mundo em que viviam e como lhe conferiam significado, esses estudos, com forte tendência etnográfica, encontram nos contos recolhidos da tradição oral europeia uma real possibilidade de acesso àquelas mentes porque eles são capazes de revelar um material cultural extremamente rico para a compreensão histórica da mentalidade daqueles grupos sociais constituídos em outro tempo.

Se os contos, narrados nas rodas camponesas dos séculos XVII e XVIII, são uma via promissora de acesso para compreender como as pessoas comuns, do século das luzes e do Antigo Regime francês, organizavam a realidade em suas mentes, se expressavam por determinados tipos de comportamentos e revelavam estratégias de sobrevivência exigidas pela vida cotidiana, vejamos então, o que Darton (1986) nos indica quando reproduz um conto narrado nas rodas camponesas, da França iluminista.

Certo dia, a mãe de uma menina mandou que ela levasse um pouco de pão e de leite para a sua vó. Quando a menina ia caminhando pela floresta, um lobo aproximou-se e perguntou-lhe para onde se dirigia.

- Para a casa de vovó - ela respondeu.

- Por que caminho você vai, o dos alfinetes ou o das agulhas?

- $O$ das agulhas.

Então, o lobo seguiu pelo caminho dos alfinetes e chegou primeiro à casa. Matou a avó, despejou seu sangue numa garrafa e cortou sua carne em fatias, colocando tudo numa travessa. Depois, vestiu sua roupa de dormir e ficou deitado na cama, à espera.

Pam, pam. 
- Entre, querida.

- Olá vovó. Trouxe para a senhora um pouco de pão e de leite.

- Sirva-se também de alguma coisa, minha querida. Há carne e vinho na copa.

A menina comeu o que lhe era oferecido e, enquanto o fazia um gatinho disse: "Menina perdida! Comer a carne e beber o sangue de sua avó!"

Então, o lobo disse:

- Tire a roupa e deite-se na cama comigo.

- Onde ponho meu avental?

- Jogue no fogo. Você não vai mais precisar dele.

Para cada peça de roupa - corpete, saia, anágua e meias - a menina fazia a mesma pergunta. E, a cada vez, o lobo respondia:

- Jogue no fogo. Você não vai mais precisar dela.

Quando a menina se deitou na cama, disse:

- Ah, vovó! Como você é peluda!

- É para me manter mais aquecida, querida.

- Ah vovó! Que ombros largos você tem!

- É para carregar melhor a lenha, querida.

- Ah vovó! Como são compridas as suas unhas!

- É pra me coçar melhor, querida.

- Ah vovó! Que dentes grandes você tem!

- É para comer melhor você querida.

E ele a devorou. (DARTON, 1986, p.22)

Convicto de que esse conto pode revelar algo sobre a mentalidade dos camponeses do início dos tempos modernos, Darton (1986) questiona: "Mas o quê? como pode alguém partir pra uma interpretação de um texto como esse?" (p.22) Aponta então, a perspectiva de análise empreendida pelos psicanalistas Erich Fromm e Bruno Bettelheim ${ }^{1}$.

Fromm interpretou o conto como um enigma referente ao inconsciente coletivo na sociedade primitiva e decifrou-o "sem dificuldade" decodificando sua "linguagem simbólica". A história diz respeito à confrontação de uma adolescente com a sexualidade adulta, explicou ele. Seu significado oculto aparece através de seu simbolismo - mas os símbolos que ele viu, em sua versão do texto, baseavam-se em aspectos que não existiam nas versões conhecidas dos camponeses, nos séculos XVII e XVIII. Assim, ele enfatiza o (inexistente) chapeuzinho vermelho como um símbolo da menstruação e a (inexistente) garrafa que levava a menina como símbolo da virgindade: daí a (inexistente) advertência da mãe, para que ela não se desviasse do caminho entrando em regiões ermas, onde poderia quebrá-la. O lobo é o macho estuprador. E as duas (inexistentes) pedras colocadas na barriga do lobo, depois que o (inexistente) caçador retira a menina e sua avó, representam a esterilidade, a punição por infringir um tabu sexual. Assim, com uma misteriosa sensibilidade para detalhes que não apareciam no conto original, o psicanalista nos conduz para um universo mental que nunca existiu ou, pelo menos, que não existia antes do advento da psicanálise. (...) O final é particularmente importante para Bruno Bettelheim, o último da série de psicanalistas que tentaram a sorte com "Chapeuzinho Vermelho". Para ele, a chave da história, e de todas as histórias desse tipo, é a mensagem afirmativa de seu desenlace. Tendo um final feliz, declara, os contos populares permitem às crianças enfrentarem seus desejos e medos inconscientes e emergirem incólumes, o id subjugado e o ego triunfante. O id é o vilão do "Chapeuzinho Vermelho", na versão de Bettelheim. É o princípio do prazer que faz a menina se extraviar, quando já está crescida demais para a fixação oral (o estágio representado por "João e Maria") e ainda é muito nova para o sexo adulto. O id é também o lobo, que é também o pai, que é também o caçador, que é também o ego e, de alguma forma, igualmente o superego.

Darton (1986) refere-se às obras de Erich Fromm, The forgotten language: an introduction to the understanding of dreams fairy tales and myths, Nova York, 1951, p.235-41 e de Bruno Bettelheim, The Uses of Enchantment: The Meaning and Importance of Fairy Tales, Nova York, 1977, p.166-83. 
Encaminhando o lobo para sua avó, Chapeuzinho Vermelho consegue, de maneira edipiana, liquidar sua mãe, porque as mães também podem ser avós, na organização moral da alma, e as casas dos dois lados do bosque são, na verdade, a mesma casa, com em "João e Maria", no qual são, também, o corpo da mãe. Essa desembaraçada mistura de símbolos proporciona a Chapeuzinho Vermelho uma oportunidade de ir para a cama com seu pai, o lobo, dando vazão, assim, às suas fantasias edipianas. Ela sobrevive, no fim, porque renasce num nível mais elevado de existência, quando seu pai reaparece como ego-superego-caçador e corta a barriga do seu pai como lobo-id, para tirá-la de lá, e todos vivem felizes para sempre. (DARTON, 1986, p. 26)

Darton (1986), ainda a respeito da compreensão teórica elaborada por Bettelheim, acrescenta:

A interpretação dos contos populares feita por Bettelheim pode ser reduzida a quatro falsas proposições: que os contos usualmente eram dirigidos às crianças, que precisam ter sempre um final feliz, que são atemporais e que eles podem ser aplicados, em versões familiares aos norte-americanos modernos, a qualquer sociedade. (DARTON, 1986, p.338)

A partir dessas considerações, Darton (1986) denuncia a falta de preocupação de Fromm e BetteIheim com a transformação do texto. $O$ autor indica que as análises apresentadas por Bettelheim e Fromm se basearam na versão elaborada pelos Irmãos Grimm ignorando que eles recolheram o conto de Jeannette Hassenpflug, sua vizinha e amiga íntima, que ouviu o conto de sua mãe que era descendente de huguenotes e leu o conto em livro escrito por Charles Perrault que, por sua vez, recolheu o conto da tradição oral camponesa e os adaptou para os círculos elegantes de Paris, do século XVII (Darton, 1986). Considerando-os numa perspectiva atemporal, Bettelheim e Fromm desconsideraram as origens dos contos bem como os significados que possam ter tido em outros contextos.

Sabemos que os contos populares, recolhidos da tradição oral, são documentos históricos. Eles podem revelar muito sobre o modo de pensar de uma sociedade e de um tempo. Conforme Darton (1986),

Surgiram ao longo de muitos séculos e sofreram diferentes transformações em diferentes tradições culturais. Longe de expressarem as imutáveis operações do ser interno do homem, sugerem que as próprias mentalidades mudaram. Podemos avaliar a distância entre o nosso universo mental e o dos nossos ancestrais se nos imaginarmos pondo para dormir um filho nosso contando-lhe a primitiva versão camponesa do "Chapeuzinho Vermelho". (DARTON, 1986, p.26)

Com as considerações de Darton (1986) não há como discordar das recomendações que advertem sobre os riscos de anacronismo ao tomarmos os contos como atemporais. Explorar o universo das visões de mundo trazidas nos contos nos exige cuidado, atenção e, sobretudo o esforço de estarmos alertas para não tomarmos como familiar conteúdos culturais que produziram maneiras próprias de pensar em um passado remoto.

Contudo, mesmo questionando o emprego anacrônico das ideias de Fromm e Bettelheim, Darton (1986) reconheceu a existência de elementos subconscientes nos contos. Mas em seu estudo não deixa de reafirmar que a análise desse material cultural não pode prescindir da relação que os contos têm com a arte de narrar histórias e com o contexto no qual essa narrativa ocorre. O método antropológico, conforme o autor, examina o modo como o narrador reorganiza o conto adaptando-o aos ouvintes de um tempo e de um lugar, sem perder o que Ihe é essencial, o que Ihe é universal. Há, em sua perspectiva, vários estudos que podem demonstrar análises que combinam "sensibilidade com linguística, modos de narrar e contexto cultural" (DARTON,1986, p.338)²

Para identificar os trabalhos citados por Darton ver: DARTON, Robert. O grande massacre de gatos e outros episódios da história cultural francesa. Rio de Janeiro: Graal, 1986, p. 338, 339. 
As considerações apresentadas por Darton (1986) suscitam a apreciação dos estudos de Bonaventure (1992) e de Franz (1981), produzidos a partir dos referenciais teóricos da Psicologia Analítica. Assim, Bonaventure (1992) afirma que

O método redutivo de Freud, com toda a inteligência que contém, reduz as coisas a: "é apenas isto ou aquilo, ou trata-se de um complexo, ou de um recalque e nada mais". O método de amplificação das imagens, de Jung, ao fazer aproximações com as grandes imagens que as religiões ou os mitos da história humana veiculam, às vezes faz perder de vista aquilo que tem a ver com o aqui e o agora, com o que a imagem me conta, ou o conto me conta. (...) No final das contas, uma criança que perdeu sua mãe necessariamente encontrará na madrasta uma bruxa, uma mulher malvada? Nascer primeiro entre os irmãos significa ter poucas chances de se sair bem? E o irmão mais novo será sempre o vencedor? (BONAVENTURE, 1992, p.10)

Na mesma perspectiva estão as análises empreendidas por Franz (1981)

... daqui a 200 anos alguém lendo nossas interpretações poderá dizer: "Não é gozado? Eles traduziram o mito do conto de fadas para a psicologia junguiana e pensaram que era só isso e pronto! (...) E então, essas pessoas trarão uma nova interpretação e a nossa será arrolada entre tantas outras interpretações - uma ilustração de como tal material foi analisado na nossa época. Estamos bastante conscientes dessa possibilidade e de quão relativas são nossas interpretações e de que elas não encerram a verdade última. (...) Isso nos leva a afirmar que nossas interpretações nunca deverão se apresentar como "Isto é assim", o que seria uma tapeação. Numa linguagem psicológica pode-se dizer somente que o mito parece representar isso ou aquilo, e então, modernizá-lo sob essa forma. O único critério correto seria perguntar: Essa interpretação é satisfatória? Em que medida tem significado para mim e para outras pessoas? E meus sonhos concordam com ela? (...) É possível que haja outras revelações na história, mas eu alcancei os meus próprios limites e não posso ir além de mim mesma. Tenho, pois, que descansar, satisfeita, e comer o que posso digerir. Há muito alimento no simbolismo do texto, mas eu ainda não posso digeri-lo psicologicamente. (FRANZ, 1981, p. 56-57)

Darton (1986), Bonaventure (1992), e Franz (1981), mesmo pertencendo a matrizes teóricas diferentes, apresentam argumentos que se alinhavam nessa compreensão de que os contos surgiram há muitos séculos e sofreram diferentes transformações em diferentes tradições culturais; eles demonstram assim que as próprias mentalidades mudaram ao longo do tempo; os personagens dessas histórias não representam situações cotidianas encontradas permanentemente nas diferentes culturas e nos diferentes tempos históricos e são passíveis de adaptações conforme determinação histórica; as interpretações dos contos elaboradas pelas diferentes abordagens teóricas não escapam das perspectivas cultural e histórica pelas quais e nas quais são produzidas.

O debate se aquece quando consideramos as análises empreendidas pelos psicanalistas Diana Corso e Mário Corso (2006). Aprofundando os estudos empreendidos por Bettelheim, o casal Corso reconhece que Bettelheim se equivoca em sua obra quando não observa que o público leitor dos contos foi mudando ao longo da história. Contudo, apresentam as seguintes questões ao se referirem a como desenvolver uma interpretação de um Conto:

... a qual período histórico deveríamos nos ater?... esses contos atravessaram dezenas de séculos e várias formas de organização social. Qual delas teria sido mais importante na sua constituição? Estariam todos esses momentos representados nos contos, tais quais estratificações geológicas de várias eras? Ou quem sabe os contos acompanharam todas essas sociedades justamente por seus elementos a históricos? Ora, pode ser certo que os contos sejam, na origem, uma espécie de decantado de antigos ritos como quer Propp. Acreditamos que beberam também em outras fontes... Em outras palavras, o que esses contos evocam para que os povos os sigam lembrando muito tempo depois de terem sido esquecidas as possíveis experiências que os teriam criado? ... o fato é que tampouco os historiadores podem nos ajudar muito, já que exis- 
tem muitas questões não respondidas sobre a difusão e a antiguidade dos contos folclóricos. (CORSO, 2006, p.175). ${ }^{3}$

Na perspectiva desses questionamentos, os autores nos apontam uma terceira via de interpretação, iluminam o debate e impulsionam outros movimentos de análise.

\begin{abstract}
Talvez não seja o caso de contrapor o significado que os contos teriam graças à sua origem, ou seja, a constelação de ritos e mitos que os criou, portanto, uma abordagem histórica ... e uma explicação que se baseasse apenas nos elementos psicológicos que são capazes de ainda despertar em nós (no sentido do trabalho de Bettelheim). Quem sabe a saída seja um estudo interdisciplinar em que ambas as tendências possam ser levadas em consideração. Uma dá conta da origem, embora não forneça uma explicação razoável para a sua permanência. Por outro lado, as hipóteses psicológicas fornecidas pela outra esclarecem boa parte dos conteúdos e atribuem a sua permanência através das gerações à sua eficácia, mas estão longe de resolver todos os enigmas que o conto coloca. Infelizmente Bettelheim não foi influenciado por Propp, tampouco Propp deu ouvidos à Psicanálise, mas enquanto isso não acontece podemos fazer modelos aproximativos. (CORSO, 2006, p.176)
\end{abstract}

Não nos resta dúvida, por todas essas considerações, de que as compreensões que elaboramos dos contos não podem prescindir de uma análise culturalmente determinada pela situação histórica do narrador, ouvinte e ou leitor e que para compreendermos a permanência histórica de um grupo variado de contos é necessário levar em consideração o que as hipóteses psicológicas esclarecem de seus conteúdos.

\title{
Os Contos de Fadas na intervenção psicopedagógica
}

Num tempo em que os computadores demasiadamente têm invadido o cotidiano do público infantil, as crianças continuam a se encantar pelos Contos de Fadas. Sua capacidade de permanência histórica encontra-se no poder de simbolizar e apresentar "soluções" para os conflitos inconscientes que fazem parte do universo psíquico das crianças de hoje. Com os Contos de Fadas as crianças têm a possibilidade de desenvolver um repertório muito necessário para a delimitação do que é existente e do que é imaginário. Os enigmas abordados nas narrativas dos contos conferem a condição de conhecer e compreender os mistérios do mundo e dos desejos humanos. Sensivelmente, os elementos assustadores contidos nos contos e que provocam o medo - medo de ser devorado, de ser abandonado, de nossa insignificância no mundo - ensinam as crianças a desenvolverem a curiosidade, a coragem, a enfrentar as dificuldades que a vida apresenta. Por isso, contar, ler histórias é muito mais que um modo de dar prazer às crianças. Certamente, é um jeito de apoiá-las em suas angústias e possibilitar a criação de um espaço em que elas ampliem, pela fantasia, o seu pensamento.

As crianças acolhem inteiramente a ficção. Quanto mais mágica, mais fantástica for a história, melhor! E é por isso também que as crianças são sábias. Pela adesão que fazem ao mundo mágico dos contos elas ampliam o domínio da linguagem, tornam sua capacidade de pensar mais ágil e flexível e enriquecem o entendimento que formam sobre a realidade em que vivem. Nas narrativas desses contos, as crianças encontram elementos profundos que são verdadeiras ferramentas, potentes, que ao serem acolhidas favorecem a formação de seu caráter.

O estudo de Pina (2007), referenciado na abordagem da Psicologia Analítica apresenta elementos bastante importantes, que devem ser considerados no exercício de compreender a importância do conto na intervenção psicopedagógica. Conforme a autora,

Os autores citados referem-se ao trabalho de PROPP, Wladmir. As raízes históricas do conto maravilhoso. São Paulo: Martins Fontes 1997. 
Conhecendo o que realmente "conta um conto", ou seja, seu valor simbólico e psicológico, o terapeuta poderá ajudar crianças e adultos aliviando os problemas que parecem sem solução. Ao entrar em contato com bruxas, feras, dragões, ogros ou vizires que nunca estão satisfeitos (como muitos papais), os pacientes acabam percebendo que apesar de essas forças darem impressão de indestrutíveis, uma personagem de aparência frágil é capaz de derrotá-los, mostrando ser ela dotada de um grande poder. Os contos também ajudam a despotencializar a carga emocional presente nas pessoas, por deixarem de olhar seus problemas de forma tão individual. Para as crianças não é preciso nenhuma interpretação intelectual; elas não estão preocupadas com racionalizações, apenas entram na história de corpo e alma e são elas mesmas o "João e a Maria" entrando e ficando perdidos na floresta escura, tendo que descobrir recursos internos que irão ajudá-las a vencer as forças do mal. É bem verdade que para isso muitas vezes são ajudadas pelos bichos da floresta, que cuidam das tarefas psicopedagógicas como separar sementes, selecionar coisas, classificar, eleger, nomear, fazer descobertas junto às pistas, o que as crianças e os adolescentes adoram; para processar esse aprendizado precisam de muito pouca ajuda do terapeuta. (PINA, 2007, p. 5)

Pina considera fundamental a possibilidade de reviver sentimentos escondidos, conferida pelo conto. Conforme a autora, projetamos nossas imagens internas nas imagens sugeridas nos contos, o que, por fim, mobiliza uma carga de sentimentos e emoções.

As imagens e figuras arquetípicas que estão presentes nos contos e mitos nos fornecem material simbólico que nos permite trabalhar em todos os estágios da vida lidando com muitos arquétipos, principalmente com a sombra, o lado escuro da personalidade, em que se encontram os aspectos desconhecidos e geralmente desprezados por nós, como a raiva, inveja, ciúmes etc. (PINA, 2007, p.6)

Podemos identificar que os apontamentos de Pina (2007) se aproximam das contribuições de Diana e Mário Corso (2006) quando, por sua vez, indicam que

A psicanálise sente-se à vontade no terreno das narrativas, afinal, trocando em miúdos uma vida é uma história, e o que contamos dela é sempre algum tipo de ficção. A história de uma pessoa pode ser rica em aventuras, reflexões, frustrações ou mesmo pode ser insignificante, mas sempre será uma trama, da qual parcialmente escrevemos o roteiro. Frequentar as histórias imaginadas por outros, seja escutando, lendo, assistindo a filmes ou a televisão ou ainda indo ao teatro, ajuda a pensar a nossa existência sob pontos de vistas diferentes. Habitar essas vidas de fantasia é uma forma de refletir sobre destinos possíveis e cotejá-los com o nosso. Às vezes, uma história ilustra temores de que padecemos, outras, encarnam ideais ou desejos que nutrimos, em certas ocasiões iluminam cantos obscuros do nosso ser. O certo é que escolhemos aqueles enredos que nos falam de perto, mas não necessariamente de forma direta, pode ser uma identificação tangencial, enviesada. (...) Hoje os contos de fadas são considerados coisa de criança, mas curiosamente muitos deles continuam estruturalmente parecidos com aqueles que os camponeses medievais contavam. Como foi que esses restos do passado vieram parar nas mãos das crianças de hoje? (...) velhas tramas devem ter achado razões para existir em tempos tão distintos, senão teriam perecido. São problemas e soluções de outrora, mas que surpreendentemente encontraram lugar no interesse de gente novinha em folha. Por quê? (...) Se pudermos analisar histórias infantis mais recentes, mas que já se tornaram clássicas, nascidas e consagradas ao longo do século XX, buscando nelas as novas formas que a fantasia encontrou de se conjugar, talvez possamos compreender melhor algumas coisas sobre as crianças, as famílias e as pessoas do nosso tempo. Através das fantasias que embalaram os sonhos das gerações mais recentes, deve ser possível saber algo mais sobre o tipo de gente que estamos nos tornando. (CORSO, 2006, p.21)

Com os argumentos apresentados pelos autores, não nos resta dúvida de que o psicopedagogo deve fundamentalmente conhecer a que tradição o conto pertence, deve localizar sua produção na história e na cultura e precisamente identificar os conteúdos mobilizadores de reflexão sobre a existência humana que esses contos possuem e que nos trazem diferentes pontos de vista sobre a vida. É assim que poderão, os psicopedagogos, eleger contos significativos para o trabalho psicopedagógico. Observando que os personagens desses contos poten- 
cialmente alcançam a subjetividade, o psicopedagogo terá um significativo instrumento de trabalho, altamente pertinente para o desenvolvimento psicológico, social, cognitivo e afetivo da criança que atende.

\section{Considerações Finais}

Estudar sobre contos de fadas é, para além da possibilidade de elaboração teórica, uma oportunidade de acessar momentos significativos vivenciados na infância. Isto porque, em nosso tempo, esses contos, nas versões mais atuais, são destinados às crianças e constituem um material cultural muito rico, ao conferirem significados às experiências infantis, as quais incidem, sem dúvida, na compreensão de mundo que vão organizando no decorrer da vida. Quantas vezes, ao lermos essas histórias de "João e Maria", "Chapeuzinho Vermelho", "Cinderela", "Branca de Neve", "A bela adormecida do bosque", observamos as crianças ouvintes - leitoras sendo atravessadas por um processo de alívio de angústias.

As relações estabelecidas entre os estudos apresentados nesse exercício de elaboração indicam que o trabalho psicopedagógico pode ser muito exitoso se considerar os contos como ferramenta terapêutica. Espera-se, contudo, que o leitor, após ter acompanhado esse processo de reflexão, esteja inclinado a prosseguir nessa busca de significados. Com certeza, todos percebemos, nesse percurso, que estamos longe de ter palavras finais e que a história prossegue. Então, fica o desejo de que as considerações tecidas aqui possam significar uma contribuição para o desenvolvimento de outros enredos e narrativas... talvez como o prato cheio de pão e leite que foi levado, um dia, para a vovó.

\section{Referências}

BETTELHEIM, Bruno. A psicanálise dos contos de fadas. Trad. Arlene Caetano. Rio de Janeiro: Paz e Terra, 1980.

BONAVENTURE, Jette. O que Conta um Conto. São Paulo: Paulus, 1992.

CORSO, Diana Lichtenstein. CORSO, Mário. Fadas no divã. Porto Alegre: Artmed, 2006.

DARTON, Robert. $O$ grande massacre de gatos e outros episódios da história cultural francesa. Trad. Sonia Coutinho. Rio de Janeiro: Graal, 1986.

FRANZ, Marie Louise von. A Interpretação dos Contos de Fada. Trad. Maria Elci Spaccaquerche Barbosa. Rio de Janeiro: Achiamé, 1981.

PINA, Vera Márcia Gonçalves da Silva. Por trás dos Contos de Fadas. Revista Psique Ciência \& Vida, São Paulo, n.22, p. 22-31, 2007. 